\title{
General Discussion on papers of Mr T. McSweeney
}

MR E. R. Griffiths (Chairman). Any comments on this particular case please?

DR A. HARDY (G.B.). I'd just like to ask Mr McSweeney what the other phenomena of autonomic hyperreflexia were present. Did she have bradycardia, did she have sweating or was just this slight rise in blood pressure just the possibility of a fit, the only manifestation?

Mr T. MCSweEney (G.B.). In the first instance as you can appreciate we didn't see the child for about 6 weeks after her discharge and regretfully her notes, etc. from the paediatric unit are not complete. On the occasions when we have observed a fit she showed none of the other phenomena of dysreflexia.

DR A. HARDY. I would say that this was too frequent and not classical of autonomic hyperreflexia. If you put my vote it is not autonomic hyperreflexia.

DR P. Dollfus (France). What is her exact neurological status now?

Mr MCSWEENEY. She still remains a complete tetraplegic, motor and sensory below C6, in addition to which the biceps is slowly recovering. Initially a flaccid lesion, as you would expect in a child, but there is now spasticity of all four limbs, enhanced on the left side.

DR P. Dollfus. Was an air myelogram contemplated or performed.

MR MCSWEENEY. No, not an air myelogram.

DR H. Frankel (G.B.). If we are inviting guesses as to the cause of continuing fits, I think it is possible that the original injury caused terrible damage. In a child I think its deep unconsciousness at the beginning would not necessarily be a feature of that. I think that the upright position she adopted may have caused hypotensive cerebral damage, perhaps associated with hypoglycaemia as well, and I do wonder whether the upright position in an infant, well virtually an infant, a child too young to say what if anything she feels is wrong might be hazardous, although I saw the child at that time and she was obviously well supervised during all such periods. I would have thought it would have been noted. I think that an episode of hypertensive crisis of autonomic dysreflexia causing cerebral haemorrhage or intracerebral haemorrhage is probably the most likely in view of the continuing fits that have occurred since then and I don't think you need further rises of blood pressure, the damage is there and it needs to be controlled with drugs, probably for the rest of her life.

DR J. WaLSH (G.B.). The one thing that I can't understand is the occurrence of spasticity so long afterwards. Presumably because the lesion is a C6 lesion it is a traction lesion and the top part of the cord escaped. You said that the child had breathing immediately after injury. Now how can you say from an intercranial lesion produce spasticity to a so completely damaged cord, if the cord is completely damaged.

MR T. MCSweENEY. I've come for guidance. I think the cord is damaged as the classical childhood injury, I think it is damaged over a few segments, starting at the atrium starting at $\mathrm{C}_{5}$ and going to $\mathrm{C}_{7}$. It is interesting to speculate on the nature of this injury, I believe that the bony injury is in a sense an unassociated one. Somebody mentioned Brigg's new edition of the Mechanics of the Nervous System and I think we could invoke Brigg and say that one possibility which I can exclude by the way was that the child was hypoflexed and the discrepancy between the spinal canal and the spinal cord is such that it gives usually at about the 6th cervical segment in a child and there's no bony injury. But remember this child was within a safety harness and the bruise mark was across the chest and the harness was intact so she couldn't have had a ventro-flexion injury. On the other hand as soon as there was a dissolution in continuity in the upper cervical spine, following the dislocation, the head was free to move. The forward momentum of the head might have caused a stretch injury. Now to your point as how could a cerebral disaster affect spasticity in what we accepted almost as an anterior horn type of lesion I8 months ago, I just don't know the answer.

MR GRIFFITHS. Any further comment on this particular case? I think we thank $\mathrm{Mr}$ McSweeney for a most interesting case. 